\title{
Sheep enteric cestodes and their influence on clinical indicators used in targeted selective treatments against gastrointestinal nematodes
}

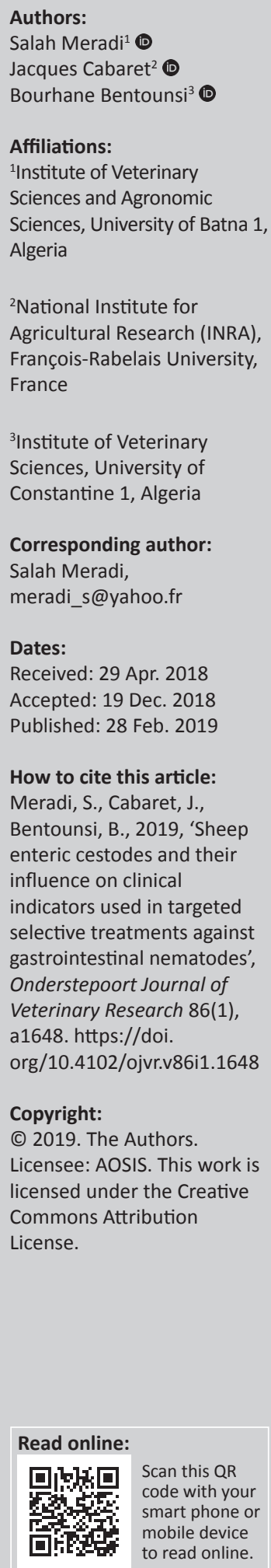

\begin{abstract}
Clinical indicators such as diarrhoea (DISCO) or anaemia $\left(\mathrm{FAMACHA}^{\oplus}\right)$ are used as a measure for targeted selective treatments against gastrointestinal nematodes (GIN). Enteric cestodes such as Moniezia may interfere directly with DISCO or indirectly with the FAMACHA ${ }^{\odot}$ score. $^{\circ}$ We investigated 821 Ouled Djellal rams naturally infected in a steppe environment (GIN alone, cestodes alone, GIN and cestodes) or not. The rams were treated with ivermectin 2 months before being slaughtered to reduce the impact of nematodes on the clinical scores; however, persistent or newly acquired GINs were not related to both scores. Of the non-infected rams $(n=296), 26 \%$ identified as needing treatment against GIN using the FAMACHA score, and $34.5 \%$ using DISCO would have been thus selected. This implies that the clinical indicators used for the targeted selective treatment of gastrointestinal nematodes are not fully reliable when a low infection is recorded and may well be influenced by confounding factors. As expected, only DISCO was affected by cestode infection, and we suggest that the presence of Moniezia should also be taken into consideration.
\end{abstract}

\section{Introduction}

A wide diversity of opinions exists regarding pathogenicity of cestodes in sheep. Cestodes from the genus Moniezia are regarded as more pathogenic in young lambs, whereas other cestode genera also recorded in adult sheep are either considered less pathogenic (Avitellina) or virtually nonpathogenic (Stilesia) (Soulsby 1982). Studies by Elliott (1984) did not consider Moniezia as a cause of diarrhoea in sheep. Conversely, Cabaret et al. (2006) found a relationship between diarrhoea in lambs and the presence of Moniezia. There is thus a real need to evaluate the influence of cestodes on sheep health and production, especially as they have marked their concomitant presence with gastrointestinal nematodes (GIN) in steppe regions in Eastern Algeria (according to unpublished data from our laboratory). Owing to the spread of anthelmintic resistance in GIN, targeted selective treatments are being undertaken only for animals identified as sick to reduce the use of anthelmintics. This is based on the fact that in a flock, the populations of gastrointestinal parasites in small ruminants are highly aggregated and dispersed (Gaba, Ginot \& Cabaret 2005). Performance indicators such as body weight (Cottle 1991; Stafford, Morgan \& Coles 2009), milk production (Hoste et al. 2002) or the use of clinical indicators, such as anaemia score using the FAMACHA ${ }^{\circ}$ system (Van Wyk \& Bath 2002), dag score (Larsen et al. 1994) and the diarrhoea score DISCO (Cabaret et al. 2006) were utilised for GIN. DISCO was found to be the most relevant indicator in the steppe regions of Eastern Algeria and Morocco (Bentounsi, Meradi \& Cabaret 2012; Ouzir et al. 2011), where Teladorsagia circumcincta, Nematodirus and Marshallagia marshalli were the most prevalent species, and Haemonchus contortus was occasionally reported (Bentounsi, Meradi \& Cabaret 2012; Meradi et al. 2011; Ouzir et al. 2011). FAMACHA ${ }^{\odot}$ scores and body weight have not been reliable indicators for detecting lambs in need of treatment in our conditions (Bentounsi, Meradi \& Cabaret 2012). The clinical impact of enteric cestodes is poorly known and could bias the selection of sheep to anthelmintic treatment against GIN. It was evaluated in this paper using clinical indicators of diarrhoea (DISCO) and anaemia $\left(\mathrm{FAMACHA}^{\circ}\right)$ obtained before slaughter of selected rams previously treated with ivermectin to also eliminate, in part, the bias owing to GIN. It was expected that the diarrhoea score would be influenced and that the FAMACHA ${ }^{\odot}$ score would remain unchanged. The evaluation of these hypotheses was undertaken in rams in Eastern Algeria.

\section{Materials and methods}

\section{Study site and experimental animals}

This study was carried out between November 2015 and February 2016 in sheep slaughtered at Batna abattoir in Eastern Algeria. Experimental animals were rams aged between 12 and 
14 months, the accepted age for slaughter. The rams investigated in the present paper are of Ouled Djellal breed, grazed under an extensive system in the region of Batna, which is characterised by a steppe climate. It is local practice to treat animals with subcutaneous injections of ivermectin 2 months before slaughter although they remain on their usual pastures. In our study, only treated rams were selected. A total of 821 rams were examined.

\section{FAMACHAC and DISCO investigations}

The FAMACHA $^{\odot}$ system is based on a semi-quantitative evaluation of the eye mucosal colour, which is classified into one of five categories on a colour chart, indicating a level of anaemia; 1 (red, non-anaemic) to 5 (white, severely anaemic) (Van Wyk \& Bath 2002). The DISCO indicator categorises a faecal sample according to the following consistency index; 1 (corresponds to normal sheep faeces in pellets), 2 (corresponds to 'soft' faeces [similar to cow pat]) and 3 (corresponds to diarrhoea [semi-liquid faeces]). These scores correlate to $40 \%, 25 \%$ and $15 \%$ dry matter in faeces, respectively (Cabaret et al. 2006). These indicators (FAMACHA ${ }^{\odot}$ and DISCO) and faecal samples were taken from each animal in lairage at the slaughterhouse. Animals under transport stress, with discomfort or that had conjunctivitis were excluded from scoring and faecal sampling.

\section{Parasitological investigations}

Faecal samples were collected per rectum to estimate GIN. The gastrointestinal infection intensity was estimated by the number of nematode eggs per gram of faeces (EPG) using a modified McMaster method with a saline solution (1.18 specific gravity) sensitive to 15 EPG (Raynaud 1970). In addition, a flotation method was performed at a sensitivity of 7.5 EPG (Raynaud 1970) when the McMaster result detected no eggs. The eggs were identified to genus level only, as Marshallagia and Nematodirus, and other GIN. After slaughter, the small intestine was washed and the content was filtered through a sieve (250 $\mu \mathrm{m}$ mesh). Cestodes were collected and transported to the Parasitology Laboratory, where the scoleces were counted and proglottids examined. The number of scoleces was used as an estimation of the number of parasites. Samples from strobila of each cestode were taken and preserved in $10 \%$ formalin. Cestodes were examined on a slide with cover glasses under a light microscope. The proglottids, after clearing and staining with acetic carmine, were identified on morphology (Soulsby 1982). Prevalence (\% of ram infected) and abundance (average number of worms among rams) were calculated (Bush et al. 1997).

\section{Statistical analysis}

The data were analysed using the statistical package SPSS version 20. The univariate analyses of variance were performed to assess the significant differences in the FAMACHA $^{\odot}$ score and DISCO in relation to infection groups. Non-parametric Spearman coefficient of correlation $\left(\mathrm{r}_{\mathrm{s}}\right)$ between clinical indicators and infection were also calculated.

\section{Ethical considerations}

The experiment was approved by the Local Ethical Committee for Experimental Animals in Algeria and was conducted in compliance with the universal ethical standards.

\section{Results}

\section{The helminth fauna}

The overall prevalence of cestodes in rams studied in the region was 9.9\%. The cestodes in decreasing order of prevalence were Moniezia expansa (5.18\%), Avitellina centripunctata (3.35\%), Stilesia globipunctata (0.97\%) and Moniezia benedeni $(0.36 \%)$. The prevalence of GIN was $57.1 \%$. The EPG was low (see Table 1). Four parasitological groups could be established: no infection (296 rams), cestode infection only (32 rams), nematode infection only (444 rams) and cestode and nematode infection (49 rams) (see Table 2).

\section{Clinical indicators (FAMACHA ${ }^{\odot}$ and DISCO)}

The FAMACHA ${ }^{\odot}$ scores extended from 1 to 4 and were found in $42.9 \%, 37.8 \%, 18.4 \%$ and $0.9 \%$ of the rams, respectively. The DISCO values (from 1 to 3 ) were $62.7 \%, 28.5 \%$ and $8.8 \%$ of the rams, respectively.

\section{Relationship between type of infection and the two clinical indicators}

DISCO was significantly ( $p=0.001)$ lower in the noninfected group and in the group with nematode infection only, and significantly ( $p=0.0001)$ higher in the group with cestode infection only. In the group harbouring cestodes and nematodes, DISCO correlated with the number of cestodes $(r s=0.67 ; p=0.0001)$ but not with nematode EPG $(r s=0.25 ; p=0.09)$. The group harbouring nematodes only had a significantly lower FAMACHA ${ }^{\odot}$ score $(p=0.003)$ (see Table 2).

TABLE 1: Distribution of gastrointestinal nematode faecal egg counts in an abattoir (821 rams) in Eastern Algeria showing faecal egg count, prevalence (\%P) and nematode categories.

\begin{tabular}{lccc}
\hline Faecal egg count & \multicolumn{3}{c}{ Nematode categories* } \\
\cline { 2 - 4 } & Marshallagia & Nematodirus & $\begin{array}{c}\text { Other gastrointestinal } \\
\text { nematodes }\end{array}$ \\
\hline 7 & 9.5 & 10.1 & 15.8 \\
15 & 1.8 & 2.7 & 6.0 \\
30 & 1.8 & 1.5 & 2.2 \\
45 and over & 1.0 & 1.1 & 0.9 \\
\hline * Prevalence (\%) & & &
\end{tabular}

TABLE 2: Clinical indicators in relation to parasitological groups of rams indicating mean abundance \pm standard deviation (MA \pm SD).

\begin{tabular}{lcc}
\hline Parasitological groups (no. of rams) & \multicolumn{2}{c}{ Clinical indicators } \\
\cline { 2 - 3 } & $\begin{array}{c}\text { FAMACHA } \\
\text { (MA } \pm \text { SD) }\end{array}$ & $\begin{array}{c}\text { DISCO } \\
\text { (MA } \pm \text { SD) }\end{array}$ \\
\hline No infection (296) & $1.90 \pm 0.80$ & $1.40 \pm 0.59$ \\
Cestode infection only (32) & $1.84 \pm 0.13$ & $1.91 \pm 0.89$ \\
Nematode infection only (444) & $1.68 \pm 0.75$ & $1.42 \pm 0.62$ \\
Cestode and nematode infection (49) & $1.82 \pm 0.81$ & $1.88 \pm 0.83$ \\
\hline
\end{tabular}

MA, mean abundance; SD, standard deviation. 


\section{Clinical indicators could select the false-positive rams for treatment}

Seventy-seven rams in the non-infected group (296 rams) had a FAMACHA $^{\odot}$ score $\geq 3$, which is often taken as an indication for treatment against GIN; however, no infection could be detected. DISCO 2 or DISCO 3 values indicate necessity for treatment. DISCO 2 or DISCO 3 were found in 86 and 16 rams, respectively, from a total of 296 rams. By using clinical indicators as the only indication of a nematode infection, 77 and 102 rams would have been incorrectly treated as false positives.

\section{Discussion and conclusion}

This low prevalence of enteric cestodes seems to be related to the steppe climate (cold semi-arid) of the region, which is unfavourable for the development of oribatid mites, intermediate hosts of cestodes (Denegri 2001). It is also probably because of the age of the sheep slaughtered (Soulsby 1982), as they were slightly over 1 year of age. Similar prevalences within sheep of similar age groups have also been reported in Turkey (4.43\%), according to Aydenizoz and Yildiz (2003), and in several regions in Eastern Algeria such as El Oued (13.2\%), Constantine (13.3\%) and Mila (12.1\%) (Bentounsi \& Meradi 2016). The very low infection rate of GIN is related to the treatment given earlier: the rams are treated mainly with ivermectin 2 months before slaughter. Nevertheless, they remained infected as some GIN are resistant (Bentounsi et al. 2007) or they become re-infected. Use of these clinical indicators, designed to detect high infection levels, could leave low infections undetected.

In the present study, DISCO was associated with cestode infection as previously shown for Moniezia by Cabaret et al. (2006). As expected, the clinical indicator, FAMACHA $^{\odot}$ score, was not influenced by cestode infection and thus remains a good indicator for some GIN (mainly Haemonchus sp.) whatever the infection with cestodes. DISCO is possibly a more general clinical indicator, being susceptible to vary to different pathogens (coccidia, GIN or Moniezia among parasites), and thus requires parasitological diagnostics to be more effective in managing gastrointestinal tract infections.

\section{Acknowledgements}

The authors are greatly indebted to the heads of the Batna abattoir, Idir Kamel and Mallem Khalid, for their help in realising this work.

\section{Competing interests}

The authors declare that they have no financial or personal relationships that may have inappropriately influenced them in writing this article.

\section{Authors' contributions}

S.M. conducted the research. B.B. conceived and directed the project and J.C. analysed the data. All authors have written and approved the final manuscript.

\section{References}

Aydenizoz, M. \& Yildiz, K., 2003, 'Prevalence of Anoplocephalidae species in sheep and cattle slaughtered in Kirikkale, Turkey', Revue Médecine Vétérinaire 154, 767-771.

Bentounsi, B., Attir, B., Meradi, S. \& Cabaret, J., 2007, 'Repeated treatment faecal egg counts to identify gastrointestinal nematode resistance in a context of low-level infection of sheep on farms in eastern Algeria', Veterinary Parasitology 144, 104-110. https://doi.org/10.1016/j.vetpar.2006.09.013

Bentounsi, B., Meradi, S. \& Cabaret, J., 2012, 'Towards finding effective indicators (diarrhoea and anaemia scores and weight gains) for the implementation of targeted selective treatment against the gastro-intestinal nematodes in lambs in a steppic environment', Veterinary Parasitology 187, 275-279. https://doi. org/10.1016/j.vetpar.2011.12.024

Bentounsi, B. \& Meradi, S., 2016, 'Cestodes Anoplocephalidae et impact clinique chez les ovins aux abattoirs de l'est algérien', Congress of the French Society of Parasitology, Grenoble, 23, 24 and 25 March 2016 (Oral communication).

Bush, A.O., Lafferty, K.D., Lotz, J.M. \& Shostak, A.W., 1997, 'Parasitology meets ecology on its own terms: Margolis et al. revisited', Journal of Parasitology 83, 575-583, viewed 22 November 2018, from http://sfp-sfmm.insight-outside.fr/ congresgrenoble2016/upload/Book_of_abstract_DEF.pdf

Cabaret, J., Gonnord, V., Cortet, J., Sauvé, C., Ballet, J., Tournadre, H. et al., 2006, 'Indicators for internal parasitic infections in organic flocks: The diarrhoea score (Disco) proposal for lambs', Organic Congress: Organic Farming and European Rural Development, Odense, Denmark, 30-31 May, 552-553, viewed 02 November 2015, from https://prodinra.inra.fr/record/33651

Cottle, D.J., 1991, Australian Sheep and Wool Handbook, Inkata Press, Melbourne.

Denegri, G.M., 2001, Cestodosis de herbívoros domésticos de la República Argentina de importancia en medicina veterinaria taxonomía, biología, epidemiología, control y tratamiento, Mar del Plata, Martín.

Elliott, D.C., 1984, 'Tapeworm (Moniezia expansa) in sheep: Anthelmintic treatment studies to assess possible pathogenic effects and production loss in young infected animals in the field', New Zealand Veterinary Journal 33(4), 52. https://doi. org/10.1080/00480169.1984.35117

Gaba, S., Ginot, V. \& Cabaret, J., 2005, 'Modelling macroparasite aggregation using a nematode-sheep system: The Weibull distribution as an alternative to the negative binomial distribution?', Parasitology 131, 393-401. https://doi. org/10.1017/S003118200500764X

Hoste, H., Chartier, C., Lefrileux, Y., Goudeau, C., Broqua, C., Pors, I. et al., 2002, 'Targeted application of anthelminthics to control trichostrongylosis in dairy goats: Result from a 2 year survey in farms', Veterinary Parasitology 110, 101-108. https://doi.org/10.1016/S0304-4017(02)00307-2

Larsen, J.W.A., Anderson, N., Vizard, A.L., Anderson, G.A. \& Hoste, H., 1994, 'Diarrhoea in Merinos ewes during winter-association with trichostrongylid larvae', Australian Veterinary Journal 71, 365-372. https://doi.org/10.1111/j.1751-0813.1994. tb00930.x

Meradi, S., Bentounsi, B., Zoued, I. \& Cabaret, J. 2011, 'The steppe species of gastrointestinal nematodes of small ruminants, with a focus on Marshallagia: Climate as a key determinant', Parasite 18, 261-269. https://doi.org/10.1051/ parasite/2011183261

Ouzir, M., Berrag, B., Benjouad, A. \& Cabaret, J. 2011, 'Use of pathophysiological indicators for decision of anthelminthic treatment of ewes against gastrointestinal nematodes in Morocco', Veterinary Parasitology 180, 372-377. https:// doi.org/10.1016/j.vetpar.2011.03.018

Raynaud, J.P., 1970, 'Etude de l'efficacité d'une technique de coproscopie quantitative pour le diagnostic de routine et le contrôle des infestations parasitaires des bovins, ovins, équins et porcins', Annales de Parasitologie Humaine \& Comparée 45, 321-334. https://doi.org/10.1051/parasite/1970453321

Soulsby, E.J.L., 1982, Helminths, arthropods and protozoa of domesticated animals, 7th edn., Baillière Tindall, London.

Stafford, K.A., Morgan, E.R. \& Coles, G.C., 2009, 'Weight-based targeted selective treatment of gastro-intestinal nematodes in a commercial sheep flock', Veterinary Parasitology 164, 59-65. https://doi.org/10.1016/j.vetpar.2009.04.009

Van Wyk, J.A. \& Bath, G.F., 2002, 'The FAMACHA ${ }^{\circ}$ system for managing haemonchosis in sheep and goats by clinically identifying individual animals for treatments', Veterinary Research 33, 437-640. https://doi.org/10.1051/vetres:2002036 